\title{
A LITERATURE STUDY OF "IMPACT OF THE COVID-19 PANDEMIC ON THE INDIAN CONSUMER BEHAVIOUR OF TOWARDS SOCIAL MEDIA."
}

\author{
Dr. Swati Kulkarni \\ Assistant Professor, SIES School of Business Studies, \\ Sector-V, Plot 1-E, Nerul East, Navi Mumbai-400706. \\ E-Mail Id: swatik@sies.edu.in, Mobile: +91 9820992990 \\ Dr. Sharmila Mohapatra, \\ Assistant Professor, SIES School of Business Studies, \\ Sector-V, Plot 1-E, Nerul East, Navi Mumbai-400706. \\ E-Mail Id: sharmilam@sies.edu.in, Mobile: +91 9930122055
}

\begin{abstract}
India is one of the most populous country in the world. In last few years, it has shown unprecedented development in its digital infrastructure. India has the second largest telecom subscribers and the $3^{\text {rd }}$ largest Internet users in the world. India is known to be young nation with $65 \%$ population below the age of 35. In 2020, the average age of an Indian is 29 years, people are more techno savvy and use Internet more. The Covid-19 pandemic has increased the social media usage in India. This research studied the impact of Covid-19 pandemic on Indian consumer behaviour towards social media. The basic objective was to study the change in behaviour of people towards social media pre and post the start of the pandemic. The literature review was done to understand this change. It was evident from the study that people have started using social media more after the pandemic was started. It was used to gather information about the products, compare the products, understand the review of products, and finally purchase of the product. The study also found out about the social media platforms that are more popular in India. It was also observed from the study that people will continue to use social media even after life will come to normal post pandemic.
\end{abstract}

Keywords: Social media, Covid-19 pandemic, Consumer purchase behaviour, Social media platforms

\section{INTRODUCTION}

India is one of the most populous country in the world. In last few years, it has shown considerable development in its digital infrastructure. India has the second largest telecom subscribers and the $3^{\text {rd }}$ largest Internet users in the world(Sarkar and Sarkar, 2019). Because of cheaper data packs, people have increased their usage of Facebook, Instagram, and Twitter. These social media is helping businesses to segment their communication to target audience. Google, Facebook, Twitter, and Instagram have become a part of everyday life of millennials.

In the first phase of lockdown during the Covid 19 pandemic, the spike in the usage of social media was observed (Masson, 2021). The average usage of individual user of social media was observed to be 3 hours and 37 minutes in June 2020 (Sandhya Killory, 2021). In 2020, India had 300,000 users, the highest number of people who were using Facebook as social media platform across the globe. Also, the same year, the highest number of WhatsApp and Tick Tock mobile app downloads in the world were recorded in India. After Jio enter the telecom market, data packs became cheaper and Internet was more accessible, more Indians had adopted for the digital lifestyle. Smart phones are increasingly becoming medium of accessing Internet for Indian consumers. In 2019, 99\% of people who were resident of rural India were recorded to use smartphones to access the Internet. This clearly shows how India has become a booming market for mobile phones as well as Internet. Since, India is known to be a young country with $65 \%$ of population of people lies in the age group of 35. A huge proportion of this social media user base were millennial and gen z. In 2018, over 73\% of Facebook users in India were between 18 and 24 years of age. India is soon to welcome 5G network. Pandemic has given a new culture of working from home. India needs $5 \mathrm{G}$ connection for better connectivity of Internet at home and to carry out business processes flawlessly. 
Video sharing platforms like YouTube had become popular in India after IPL streaming matching 2018 with over two billion views per day and of course it doubled with each IPL season thereafter. Indian music record label, Tseries shared old Bollywood and Indian pop music on YouTube and became the most viewed and subscribed YouTube channel in the world.

But the key factor for the surge in the usage of social media in India and across the world is Covid-19 pandemic. It was the defining event for the entire globe in 2020. Covid-19 pandemic caused nearly 300,000 deaths in India as on May 20, 2021 (India Ministry of Health and family welfare, 2021). To add to this, Covid 19 also created a tremendous economic burden worldwide. It cost a recession as India's GDP contracted by approximately $24 \%$ from April to June 2020(Slatter 2020). To control, the spread of virus, India announced business lockdowns, social distancing, and personal quarantines. Since, people were not able to go out for their buying and any other essential jobs because of personal contact restrictions, their usage of technology may have changed their behaviour( Barbets and Mars, 2018 and Edelman and singer, 2015).

\section{LITERATURE REVIEW}

The Covid-19 pandemic has impacted human behaviour and especially preventive health behaviours(Laato et. $\mathrm{Al}, 2020)$. People were finding it difficult to cope up with the pandemic and they were not able to understand how to behave in this situation. The study done by Mason in 2021 used the S$\mathrm{O}-\mathrm{R}$ theory to understand the change in the consumer behaviour after the Covid-19 pandemic. It also used consumer decision making model for this investigation (Nicosia, 1982). The is S-O-R theory explains how external stimuli influences the consumer behaviour (Mera Byah and Russell, 1974, Kartar et. al 2020 and Xu et.al, 2014). Using SO-R theory, it is discussed that how external stimuli influences consumer cognitive and affective processes thus affecting their behaviours. For instance, Covid 19 pandemic could be treated external stimulus which could change consumer perception leading to a change in the behaviour of people.
When studied Nicosia model, it identified five different behaviours related to consumer decision making. These behaviours are associated with identification of product needs., gathering information about products, then compare alternative product options, purchase decisions and post purchase behaviours(Nicosia, 1982).

Growing importance of social media marketing, Malik in 2016, studied what benefits derived from social media usage. The study was based on uses and gratification theory. This theory helps the researcher to understand why users are attracted to social media. The study found that users get different kind of pleasures after the use of social media: affection, attention seeking, habit, information sharing, disclosure, and social influence(Malik et al 2016). To add to this observation, another study explain social media provides temporal dissociation and divergent from passing time which results in lowering boredom(Agarwal and Kara Hannah, 2000). According to this study, users can escape unpleasant realities of life and feel empowered through a sense of control by engaging in social media. It keeps the consumer engaged by providing different product options and also by showing the comparison between different brands and marketing information about these brands(yuksel et al, 2016).

People were scared of physical contact with others during the Covid- 19 pandemic and that is the reason why people started using social media more, to interact with others(Knowles et al, 2020).It was difficult for businesses to communicate with consumers directly because of social distance and norms. Social media came as a rescue for business organisations in this pandemic time (Root, 2020).

The study done by Mason et.al in 2020 found that people have increased their social media usage to search for a product, gather more information about a product or brand, compare product features with other brands, purchase a product or even to give a review or feedback for the purchased product. These observations provided the basis of the study done by Mason et.al., 2021. The study was based on Indian consumers social media 
marketing behaviour during Covid- 19 pandemic.

2.1 Identifying product needs and social media According to consumer decision making process, stage one is to identify the need of the product. This need is identified by the consumer's understanding of the difference between the current and the desired states of being (Bruner, 1987).Business can stimulate consumer's product need by creating brand awareness on social media. Businesses can talk about positive aspects of brand or product on social media (Thota 2018). These needs of consumers are stimulated by photos, videos, pictures shared either by business firms or other users of a product (Josh Ariane Roosta me, 2017). For instance, businesses can highlight the reviews posted by satisfied customers. They can also post the photos, videos, or reviews of social media influencers either to create influencing stimuli or to increase product awareness (words, 2019).

2.2 Product information searches and social media

Since, restrictions like lockdown and social distancing in imposed due to Covid 19 pandemic, people had opted for social media to gather more information about different products and brands. Developed technologies and changed consumer behaviour has resulted in the increased use of social media for gathering information and for marketing communication (Tam and Jeong-Nam, 2019).

2.3 Evaluating product and social media.

2.4

While evaluating products, consumers seek information on price, opinion leaders views and trending fashion. Social media allows businesses to interact with customers in twoway communication and also use the appropriate influencing cue so that customers will develop positive perception about the product. Social media helps consumers to reduce perceived risk by allowing them to take opinions by opinion leaders, perceived experts, friends, and family (Delemer, 1990 \& Voyer et. al, 2015). Social media helps consumer in making informed decisions about the benefits and risks associated. It helps consumer in making informed decisions about the benefits and risks associated with a given product. Therefore, consumer take help of social media to reduce the risk before making a purchase decision.

\subsection{Purchase decisions and social media}

Social media is normally used more for understanding and comparing product or brand information. But still some platform also allows for making a purchase.

2.5 Post purchase behaviour and social media Social media allows giving feedback or grievances once customer has made a purchase. Business firms take a note and reach to customer in case of dissatisfaction for the product.

Dr. Karan Sudarland in his blog on Palgrave Macmillan have discussed three situations when businesses wish to reach to the consumer. Social media play a key role in all these three situations.

2.6 Launching a new product/ service as a response to the changing environment

COVID-19 pandemic put restrictions like lockdown, work from home and social distancing. This made businesses to offer online purchases and contact free delivery of the product. Paid and organic social media posts are extremely effective way of promoting new products or services to current and prospective customers. Paid advertisements on social media like Facebook and Instagram can reach high population of targeted customers within a particular geographical area which are related directly to your brand and are from specific age group.

Report from Edelman Trust Barometer shows the impact of COVID-19 pandemic on Indian businesses and government organisations. It is observed from the report that the trust level of people in general news and information published on social media had gone up to $70 \%$ in 2020 from $66 \%$ in 2019. But in 2021, it has observed to come down to $68 \%$.Also, the report shows that $84 \%$ responding that brand advertising needs to focus on how people can co-up with new normal after end of the pandemic.

Since people are still in panic mode, Dr. Karen feels that brands and another business firms should help people more than just selling. Business firms should focus more on how their products or services will help people in 
this situation rather than focusing on hard sells. Current and potential customers will value this helping hand more than anything else.

Social media can be used more to increase the customer engagement.

Since, people are still not able to move freely dure to restriction in India, it is perfect time for businesses to increase their social media activities to help them in their routine and also entertain them. Businesses should help customers with some ideas and activities which will make their life easier and joyful during the pandemic. Since, people were not able to buy their regular products it is good idea to create content on social media which can help customers to temporarily make or use product or service which is relevant to your business. For instance, salon can help people by giving some beauty tips or some
The same report also found that $60 \%$ of people in India have moved to new brand since the Covid-19 pandemic make has started because of their innovative and compassionate way of responding to customers. Thus, businesses are making efforts to build their customer relationship by engaging them and helping them through social media.

The other reason in the rise of social media users first country wide lockdown during the cold 19 pandemic. People were not used to sit at home so much during the lockdown and hence started using social media to escape their boredom. People started using Facebook, Instagram, Twitter, Snapchat For their entertainment, shopping, information gathering and learning. In the year 2020, Instagram had one billion monthly active users. Earlier, Instagram was used to share photographs and videos but now it has become a potential market for business

\section{Many consumers intend to continue these habits even after the crisis is over}

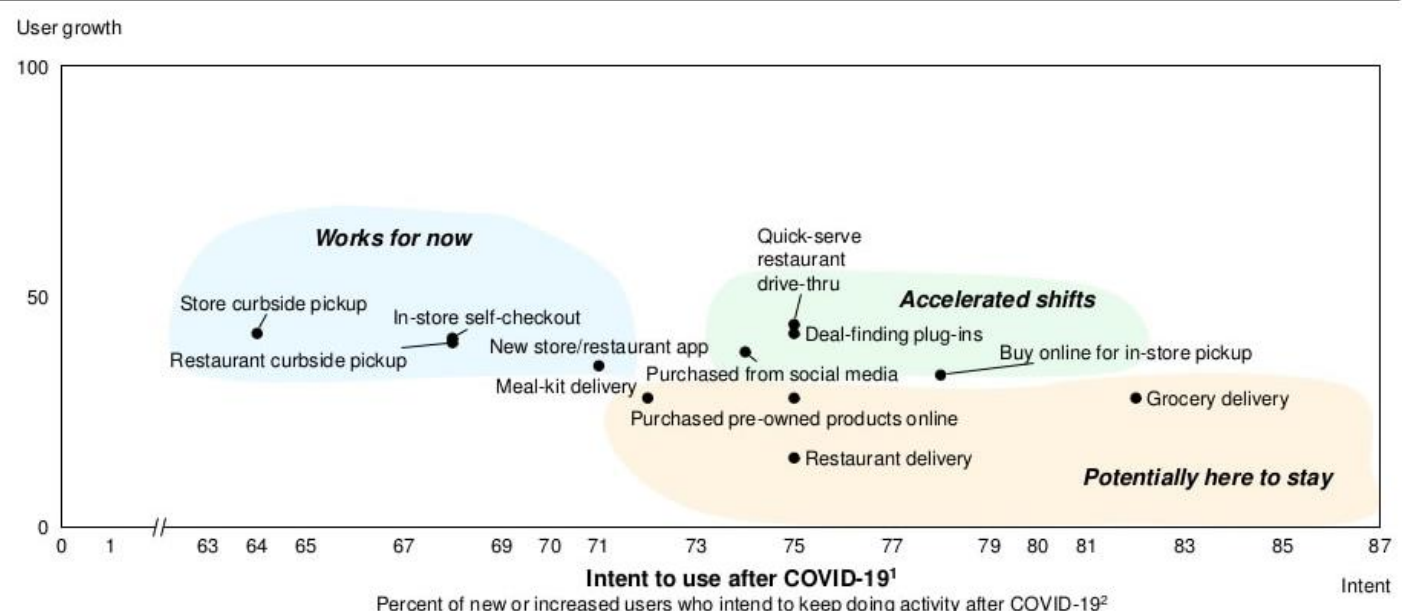

Source: McKinsey and Company Covid-19 India Consumer Pulse Survey, December 10, 2020

home remedies for treatment. Gym trainers can guide people on exercises which can be done at home. Other engaging activity can be competitions where customers have to share video of them performing a particular task. By doing this, customers can enjoy and learn at the same time. The Edelman Trust Barometer's special report says that $83 \%$ of people feel that CEOs of business firm should take initiatives to help common people in this pandemic and $76 \%$ people feel that CEO's should take the lead and should not wait for the government to impose change during the pandemic time. organizations. Since Instagram can reach huge potential market to $928.51000,000$ people, businesses are investing more in marketing through Instagram. Influencer marketing has become an effective way of business for organizations.

Avinash ginger, Marketing Head of Thomas Cook explain the transition from search marketing to social media marketing during Covid-19 pandemic.

According to McKensey report on Covid-19 India consumer pulse survey in 2020, 
approximately $75 \%$ consumers intend to continue their habit of purchase products through social media. This shows the business opportunities, organizations have in social media marketing.

Business firms are making use of influencer marketing and competitions to keep the customers engaged in social media. It helps firms to keep the business relations with their customers by having two-way communication. Also, their report says about $45 \%$ of people have started using social media for different activities Since Covid-19 started.

People were asked if they will remain on social media even after life comes to normalcy and approximately $70 \%$ people would continue the use of social media, according to the report. the Covid 19 pandemic. The results showed that the consumer started using more social media to identify the product to fulfil their need once the pandemic had begun. Indian Consumer's social media shopping activity has increased post pandemic. It was found from literature that the use of social media for shopping has increased during the pandemic and people would like to continue their usage even after the life comes to normalcy. Since, there were restrictions imposed on people like lockdown, social distancing, people were using social media to identify the products or service which can satisfy their need. Also, they were comparing different available products on social media. People were fearing of virus, they were scared to have any contact with outside world and hence making a purchase on social media. That is the reason, why there was a hike in shopping activity through social media.

\section{Many consumers intend to continue these habits even after the crisis is over}

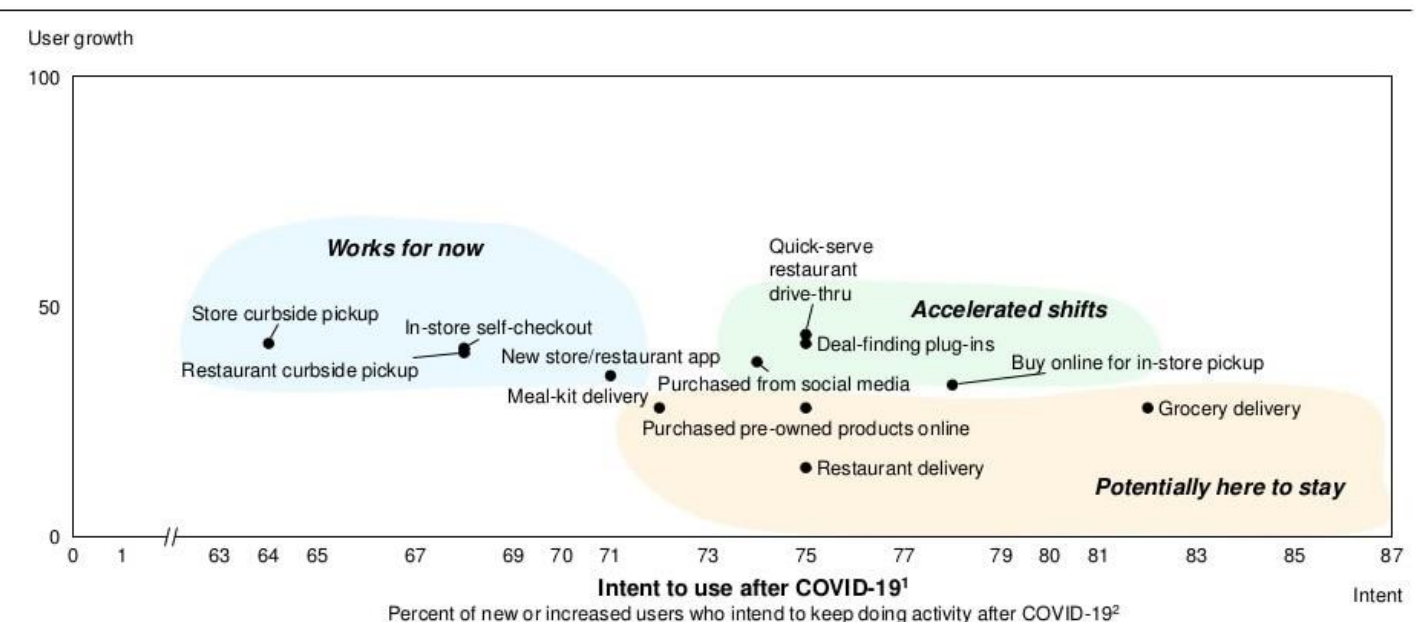

Source: McKinsey and Company Covid-19 India Consumer Pulse Survey, December 10, 2020

People use social media for identify the product needs, to search the information about product, compare different products that are available in the market, actual purchase of the product and then for writing reviews or feedback about a purchased product. COVID19 pandemic made lot of people to move to social media for gathering information about a product before its purchase.

\section{FINDINGS AND DISCUSSION}

The research study done by Masson et al in 2021 used the Wilcon signed rank test to understand the change in the behaviour of people towards social media before and after
In India, which social media platform people were comfortable with pre and post the start of the Covid-19 pandemic was found out. While there was no significant change observed in platform preferences, a slight increase in the use of Instagram and a slight decrease in the use of YouTube was observed. Since, Indian consumers have increased their usage of social media for information gathering of product they need, business firm need to engage their consumers regularly. Organization should convey positive attributes so that consumer will develop the trust about the product that will satisfy their need. Once, a consumer has purchased the 
product, business firm should encourage them to write a review on social media platform about how their need was satisfied after the purchase of the product.

As discussed earlier, consumers have increased their use of social media to gather information about products, see more products that are available, compare the products and make the final purchase. If consumers are using social media for almost everything pre and post purchase of product it is important for businesses to establish the communication with consumers by using social media. Businesses use analytics to understand consumers interest before establishing communication with them. It is suggested that organisations can use tweets, videos to create a buzz among consumers according to their products need.

Businesses also segment the customers according to low and high involvement while buying the product. To attract more customers, businesses usually take reviews of customers who are highly satisfied with their product. It develops positive perceptions in the mind of consumer about the product. Also sharing positive comments by influencer or key opinion leader can also help to enhance a business. It helps in generating brand awareness, interest or even purchase of a product. Business organization should also engage the consumer by updating the content regularly on social media.

Though in all cultures, consumer behaviour towards social media is observed to be similar, the social media platforms used by people are different. So, it is important to choose the right social media platform to reach the maximum number of people in India. Businesses should continuously identify and use Indian consumer preferred platform in their social media marketing strategy. It is important in country like India with massive population and increased Internet access. Professional social media platforms like LinkedIn helped companies to hire people for critical role in this pandemic time.

\section{CONCLUSION}

The growing use of social media to influence consumer behaviour is evident. During the Covid-19 pandemic, people have moved to social media for many reasons. Their movement from traditional buying to buying through social media has made it more influential platform. The literature review shows the impact of social media on consumers decision making behaviour. During the Covid 19 pandemic. Businesses should use the effective marketing strategies to keep the existing customers and add new ones to the database.

Social media is a key factor to enhance the brand through increase brand awareness and preference. It is evident that people have started using social media more after the start of the Covid-19 pandemic. They have also increased the online consumer behaviour activities. Since, it was analysed that people are going to stay with social media even after the life comes to normalcy, businesses should make social media strategies to account for social media platform preferences and practices in India. It is also recommended that business organization should also keep their relaunch strategy ready once the life will come to normal and restrictions will be finished. Create a marketing communication strategy with strong focus on social media.

\section{REFERENCES:}

Laato, S., lslam, A. N., Farooq, A., \& Dhir, A. (2020). Unusual purchasing behaviour during the early stages of the COVID-19 pandemic: The stimulus-organismresponse approach. Journal of Retailing and Consumer Services, 57, 102224. Accessed on October 31, 2020, available online at: https://doi.org/10.1016/ j.jretconser.2020.102224

Mason, A. (2020). Coronavirus disrupts the United States economy: A preliminary conceptual investigation. Journal of International Business and Economics, $20 \quad$ (3), 77-85. http:/ /dx.doi.org/10.18374/JIBE-20-3.6

Mason, A., Narcum, J., \& Mason, K. (2020). Changes in consumer decision-making resulting from the COVID-19 pandemic. Journal of Customer Behaviour, 19(4), 299-321. Available online at. https://doi.org/10. 1362/147539220X16003502334181

Mason, A., Narcum, J., Mason, K., \& Awan, U. (2021). Social media marketing gains importance after Covid-19. Cogent 
Business and Management, 8(1), 1870797.

https://doi.org/10.1080/23311975.2020. 1870797

Mehrabian, A., \& Russell, J. (1974). An approach to environmental psychology. MIT Press.

Thota, S. (2018). Social media: A conceptual model of the why's, when's and how's of consumer usage of social media and implications on business strategies. Academy of Marketing Studies Journal, 22(3), $1-12$. https://www.abacademies.org/articles / socialmedia- a-conceptual-model-ofthe-whys-whensand-howsofconsumer-usage-of-social-mediaandimplica tions-on-business-strategi7531.html

Malik, A., Dhir, A., \& Nieminen, M. (2016). Uses and gratifications of digital photo sharing on Facebook. Telematics and Informatics, 33(1), 129-138. https:// doi.org/10.1016/j.tele.2015.06.009

Wertz, J. (2019). How business and influencers are monetizing Instagram, Forbes. Published on Dec 31, 2019, at https://www.forbes.com/sites/jiawertz /2020/12/ 31/how-businesses-andinfluencers-are-monetizingInstagram/\#5d0b4b8f1078

Nicosia, F. (1982). Consumer decision processes: A futuristic view. Advances in Consumer Research, 9 (1), 17-19.

Agarwal, R., \& Karahanna, E. (2000). Time flies when you're having fun: Cognitive absorption and beliefs about information technology usage. MIS Quarterly, 24(4), 665-694. https://doi.org/10.2307/3250951

Knowles, J., Ettenson, R., Lynch, P., \& Dollens, J. (2020). Growth opportunities for brands during the COVID-19 crisis. MIT Sloan Management Review: Cambridge, $61 \quad(4), \quad 2-6$. https:/ /libcatalog.atu.edu:443/login?url $=$

https://www.proquest.com/scholarlyjournals/ growth-opportunities-brandsduring-covid-19/doc view $/ 2406643113 /$ se-2?accountid=8364
Root, A. (2020). Social distancing' will hit the best- performing restaurant stocks. Here's how bad it could get. Barons Online. Published online on March 16, 2020,

at https://search.proquest.com/abicomple te/docview/2377259642/fulltext/391FA 67D87B54A2BPQ/3? accountid=8364.

Accessed on May 28, 2020.

Sarkar, S., \& Sarkar, P. (2019). Data monetization strategies for new age digital communication providers in India. Telecom Business Review, 12(1), 23-34. http:/ / 52.172.152.24/index.php/tbr/article/vie $\mathrm{w} / 190562$

Slater, J. (2020). India's economy contracts by nearly 24 percent, its sharpest drop on record. The Washington Post. Published on Aug. 31, 2020. Available online at https://www.washingtonpost.com/wo rld/asia_pacific/indias-economycontracts-by-nearly-24-percent- amidpandemic/2020/08/31/92318fbe-eb7011ea- bd08-1b10132b458f_story.html.

Xu, J., Benbasat, I., \& Cenfetelli, R. (2014). The nature and consequences of trade-off transparency in the context of recommendation agents. MIS Quarterly, 38(2), 379-406. https://doi.org/10.25300/MISQ/2014/ 38.2.03

Yuksel, M., Milne, G., \& Miller, E. (2016). Social media as complementary consumption: The relationship between consumer empowerment and social interactions in experiential and informative contexts. Journal of Consumer Marketing, 33(2), 111-123. https:/ / doi.org/10.1108/JCM-04-20151396

Bruner, G. (1987). The effect of problem recognition style on information seeking. Journal of the Academy of Marketing Science, 15(4), 33-41. https://doi.org/10. 1007/BF02723288

Barwitz, N., \& Maas, P. (2018). Understanding the omnichannel customer journey: Determinants of tion choice. Journal of Interactive Marketing, 43, 116-133. https://doi.org/10.1016/j.intmar.2018.0 2.001 
Kumar, S., Dhir, A., Talwar, S., Chakraborty, D., \& Kaur, P. (2020). What drives brand love for natural products? The moderating role of household size. Journal of Retailing and Consumer Services, 58, 1-10. Accessed on October 28, 2020, Available online at: https://doi.

org/10.1016/j.jretconser.2020.102329.

Delener, N. (1990). The effects of religious factors on perceived risk in durable goods purchase decisions. Journal of Consumer Marketing, 7(3), 27-39. https:// doi.org/10.1108/EUM0000000002580

Tam, L., \& Jeong-Nam, K. (2019). Social media analytics: How they support company public relations. Journal of Business Strategy, $\quad 40(1), \quad 28-34$. http://dx.doi.org/ 10.1108/JBS-06-20170078

Jashari, F., \& Rrustemi, V. (2017). The impact of social media on consumer behaviourcase study. Journal of Knowledge Management, Economics, and
Information Technology, 7(1), 1-21. https://www.scientificpapers. org/wpcontent/files/1579_Fitore_JashariVisar_ Rrustemi-

The_impact_of_social_media_on_consu mer_behavior.pdf

Voyer, P., Ranaweera, C., \& Laszlo Sajtos, D. (2015). The impact of word of mouth on service purchase decisions: Examining risk and the interaction of tie strength and involvement. Journal of Service Theory and Practice, 25(5), 636-656. https://doi.org/10.1108/ JSTP-04-20140070

Jashari, F., \& Rrustemi, V. (2017). The impact of social media on consumer behaviourcase study. Journal of Knowledge Management, Economics, and Information Technology, 7(1), 1-21. https://www.scientificpapers. org/wpcontent/files/1579_Fitore_JashariVisar_ Rrustemi-

The_impact_of_social_media_on_consu mer_behavior.pdf 